\title{
Theories, Vectors, and Computer Models: Marine Invasion Science in the Anthropocene
}

\author{
Philipp Laeseke, Jessica Schiller, Jonas Letschert, \\ and Sara Doolittle Llanos
}

\begin{abstract}
Marine invasions are well-recognized as a worldwide threat to biodiversity and cause for tremendous economic damage. Fundamental aspects in invasion ecology are not yet fully understood, as there is neither a clear definition of invasive species nor their characteristics. Likewise, regulations to tackle marine invasions are fragmentary and either restricted to specific regions or certain aspects of the invasion process. Nonetheless, marine anthropogenic vectors (e.g., vessel fouling, ballast water, aquaculture, marine static structures, floating debris, and human-mediated climate change) are well described. The most important distribution vector for marine nonindigenous species is the shipping sector, composed by vessel fouling and ballast water discharge. Ship traffic is a constantly growing sector, as not only ship sizes are increasing, but also remote environments such as the polar regions are becoming accessible for commercial use. To mitigate invasions, it is necessary to evaluate species' capability to invade a certain habitat, as well as the risk of a region of becoming invaded. On an ecological level, this may be achieved by Ecological Niche Modelling based on environmental data. In combination with quantitative vector data, sophisticated species distribution models may be developed. Especially the ever-increasing amount of available data allows for comprehensive modelling approaches to predict marine invasions and provide valuable information for policy makers. For this article,
\end{abstract}

All authors equally contributed to this chapter.

P. Laeseke $(\bowtie) \cdot J$. Schiller

Marine Botany, University of Bremen, Bremen, Germany

e-mail: philipp.laeseke@uni-bremen.de

J. Letschert

Leibniz Centre for Tropical Marine Research (ZMT),

Bremen, Germany

S. D. Llanos

Groningen Institute for Evolutionary Life-Sciences GELIFES,

University of Groningen, Groningen, The Netherlands we reviewed available literature to provide brief insights into the backgrounds and regulations of major marine vectors, as well as species distribution modelling. Finally, we present some state-of-the-art modelling approaches based on ecological and vector data, beneficial for realistic risk assessments.

\section{Keywords}

Non-indigenous species $\cdot$ Marine vectors $\cdot$ Species distribution modelling $\cdot$ Regulations $\cdot$ Anthropogenic debris

\subsection{Non-indigenous and Invasive Species}

Non-indigenous species (NIS) can have negative effects on receiving ecosystems and are considered one of the major global threats to biodiversity (Ruiz et al. 1997; Casas et al. 2004; Raffo et al. 2009). Apart from ecological consequences, substantial economic damage can be caused by overly abundant introduced species or harmful species such as pathogens (e.g., Pimentel et al. 2000, 2001). The effects of introductions and establishments of new species in a community are unpredictable, as a multitude of biotic and abiotic factors determine the onset and further development of an invasion. Depending on the receiving habitat and the observed parameter, the same species can have negative but also positive effects (McLaughlan et al. 2014). Because of the variety of factors of each invasion, understanding them on the species-, pathway-, and ecosystem level is essential for adequate evaluation and possible management.

Despite their ecological and economic relevance, not even the basic terminology of introduced or invasive species is clearly determined among scientists and regulations. Over time, several definitions have been proposed for biological invasions. The most basic one is being a non-indigenous 
species (NIS), namely, a species introduced after the discovery of America and the onset of large-scale transatlantic ship traffic (Leppäkoski et al. 2013; Ricciardi et al. 2013). More specifically, Richardson and Pyšek (2006) defined invasion ecology as the study of human-mediated introductions of species to areas beyond their native range without considering the impact on the invaded habitat. Alpert et al. (2000) included effects of NIS and described an invasive species as "one that both spreads in space and has negative effects on species already in the space that it enters." According to Boudouresque and Verlaque (2002) introduced and invasive species can be differentiated by the conspicuous role the latter play in the recipient ecosystems, which is characterized by becoming dominant and potentially taking the place of keystone species. The previous examples show how much definitions can vary in only a few studies - with more being considered, they even begin to contradict each other, both in terminology and procedure (e.g., Blackburn et al. 2011; Guy-Haim et al. 2018).

Although not clearly defined, bioinvasions are a topic of public interest (García-Llorente et al. 2008) and there are several national eradication programs and policies established (see New Zealand, USA; Myers et al. 2000, Wotton et al. 2004). However, on a global scale, overarching regulations to mitigate marine invasions are missing. This is reflected in the EU legislative 1143/2014, which only deals with anthropogenically introduced species, but does not consider naturally introduced species. Moreover, international conventions for marine traffic are not binding across the globe or only concern certain aspects of dispersal mechanisms (see Sect. 10.2). One reason for this fragmentation among marine NIS regulations might be the influence of economic interests, which dilute scientific expertise (Margolis et al. 2005).

To develop efficient regulations, it is essential to gain an in-depth understanding of human-mediated vectors and factors influencing invasion success. Ecological Niche Models (ENM) can be powerful in evaluating invasion potential and are currently implemented at the frontier of invasion science (see Sect. 10.3). Figure 10.1 sets the framework for this article, in which we summarize knowledge on anthropogenic vectors and give insights into methods and developments of ENM as a potential forecasting tool. We intend to contribute to the understanding of bioinvasions at a broader scale and shine a light on necessary future efforts to develop efficient regulations.

\subsection{Anthropogenic Vectors}

Defining which vector has the highest impact in terms of the number of introductions, establishment rate, and effects on the new habitat is challenging because their effectiveness and frequency vary with time and geographical region (Williams et al. 2013). In general, failed introductions and invasions pose a problem in cross-vector analysis, because they mostly remain hidden, leading to strong biases in introduction rates per vector (Zenni and Nuñez 2013). About four decades ago, ship traffic and aquaculture were identified as the major vectors for marine human-mediated introductions (Carlton 1979). Recent studies suggest that this assumption has not changed much and efforts have been undertaken to rank vectors regarding their potential of dispersing NIS. On a global level, a positive correlation between cargo ship traffic and marine introductions reveals the vast contribution of marine traffic to create connectivity across distant geographic regions (Seebens et al. 2016). Ship traffic can be divided into two NIS pathways: the colonization of vessel hulls with sessile or small motile species (hereafter fouling species), and the transportation of organisms and their earlylife stages (eggs, larvae) in ballast water tanks (Ruiz et al. 1997; Cohen and Carlton 1998; Godwin 2003). On a regional level, a cross-vector comparison in California revealed vessel fouling as the most important vector followed by ballast water and aquaculture (Williams et al. 2013). However, the authors claim that results cannot be extrapolated and are case-specific with respect to area, time, and vector composition.

This review examines the following marine vectors: vessel fouling, ballast water, mariculture, marine static structures, floating anthropogenic litter, and human-mediated climate change. This selection encompasses the major vectors, affecting most marine ecosystems worldwide. Live species trade with ornamental (Weigle et al. 2005) and bait species (Weigle et al. 2005; Fowler et al. 2016) represent minor vectors and therefore will not be elaborated in this article. Canals play an important role in the distribution of marine species on regional scales (see Gollasch 2006 for the influence of the Suez Canal on Mediterranean species composition). However, they represent the removal of physical barriers between adjacent regions and allow migration in a variety of ways (e.g., shipping related or natural dispersal), which are covered in the sections mentioned above. Therefore, we do not include an individual chapter on this vector.

\subsubsection{Vessel Fouling}

The importance of hull fouling for marine invasions is unquestionable. A convenient parameter to quantify the marine invasion risk through hull fouling is the wetted surface area (WSA) of ships (Miller et al. 2018) and an approach of calculating the WSA of the world fleet of commercial vessels resulted in $325 \times 10^{6} \mathrm{~m}^{2}$ (Moser et al. 2016). Marine traffic is continuously increasing and even remote areas, such as 


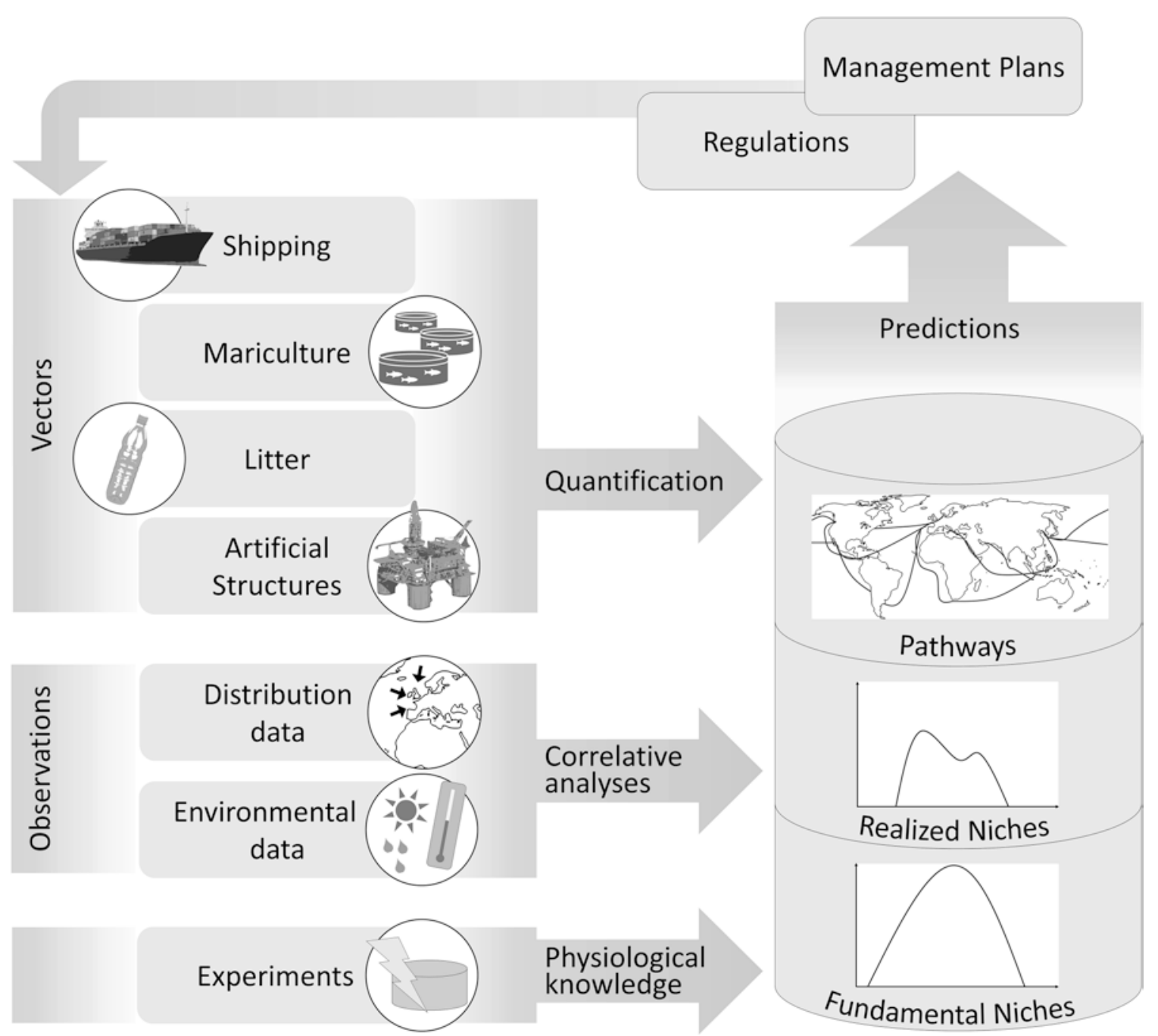

Fig. 10.1 Marine Bioinvasions in the Anthropocene: the most important vectors for alien invasive species across geographic regions are anthropogenic transportation means, such as shipping- and mariculturerelated transfers. Also passively drifting litter and stable structures contribute to the transport and introduction of species. Quantification of introductions along these vectors allows for identification of major pathways across the globe. Ecological Niche Modelling can help to identify suitable environmental conditions for species in question. While correlative approaches are well established for the investigation

the Arctic, become available for commercial shipping due to melting sea ice (Miller and Ruiz 2014).

Antifouling coatings are applied to vessel hulls and repel many fouling species that would normally settle on submerged vessel areas (Williams et al. 2013). Yet, there are certain organisms that are immune to antifouling components such as the bryozoan Watersipora subtorquata, which may serve as a foundation species providing settlement space for subsequent epibionts (Floerl et al. 2004). Small disruptions of 1-2 cm in antifouling coatings may enable the settlement of a wide range of sessile marine species, which can easily of realized niches, laboratory studies can yield important additional information about the species' fundamental niche and hence contribute to the understanding of ecological mechanisms which influence a species' distribution potential. Transportation data and Ecological Niche Models can be combined to evaluate invasion risk. Identification of areas with high introduction pressure and understanding of the species being transported along are an important step prior to the development of regulations, management plans, and mitigation strategies. However, to date, only few international regulations are effective which successfully control the spread of species

be overseen in cryptic spots like keels or propeller shafts (Piola and Johnston 2008). Godwin (2003) observed weaknesses of antifouling coatings at weld seams and spots where smaller boats were placed on wooden blocks while painted. $\mathrm{He}$ also assumed that slow velocities and long port stays increase the potential of sessile species to settle and survive on vessel hulls (Godwin 2003). Kauano et al. (2017) tested persistence of fouling species after being dragged with 5, 15, and 20 knots for $20 \mathrm{~min}$. Although the overall trend shows a negative correlation between velocity and persistence, $90 \%$ of the species were present with at least $20 \%$ of their original 
abundance after being dragged with 20 knots. Some limitation to vessel fouling is provided by desiccation. Kauano et al. (2017) found that most soft-bodied sessile species died after being outside of the water for 24 hours, whereas barnacles survived 120 hours. Another example for desiccation resistance are sporophytes of the invasive kelp Undaria pinnatifida that released viable spores even after 3 days outside of the water (Bollen et al. 2017).

Large cargo vessels such as bulk carriers, tankers, and container ships are usually equipped with slow-speed engines (Endresen et al. 2003), meaning that they rarely travel faster than 20 knots, and are only put on dry dock every 5 years when their hulls are cleaned and repainted. Yet, these vessels represent $79 \%$ of the WSA of the commercial world fleet and substantially contribute to geographical connectivity (Moser et al. 2016; Seebens et al. 2016). In combination with the knowledge mentioned above, this may explain why vessel fouling is still a major pathway for NIS on a global scale.

Trends in the marine traffic industry favor larger container ships and hub-ports (Shenkar and Rosen 2018), from which smaller transport vessels carry goods to smaller ports, representing one example of secondary spread. Small-scale boating may contribute to secondary spread of NIS, especially in areas with intense tourism or recreational activities (Anderson et al. 2015). Many marine invertebrates, such as ascidians and bryozoans, have very short natural dispersal ranges and hence marine traffic or rafting debris is likely to enable their long-range dispersal (Petersen and Svane 1995). This is underlined by a case study in the great barrier reef where sessile NIS were found about $80 \mathrm{~km}$ offshore at an isolated coral reef that is frequently visited by boats (Piola and Johnston 2008).

In 2011, the International Marine Organization (IMO) published a resolution for the responsible management of vessel fouling to reduce the risk of NIS introduction (IMO 2011). However, these are mere voluntary guidelines and despite the global significance of vessel fouling for NIS dispersal, there is no enforced regulation on an international level yet. There are some examples for implemented hull fouling standards on a national and regional level represented by New Zealand (Ministry for Primary Industries 2014), and the National Park of Galapagos, Ecuador (Campbell et al. 2015). Both regulations require clean vessel hulls and antifouling coatings prior to the arrival of vessels.

\subsubsection{Ballast Water}

Ballast water discharge is the vector with the most management rules among the important anthropogenic dispersal mechanisms. The International Convention for the Control and Management of Ships' Ballast Water and Sediments (hereafter the BW Convention) was adopted by the IMO in 2004 and came into force in September 2017 (IMO 2004). According to requirements regulating the behavior of ballast water discharge, the BW Convention can be split into two major parts.

The first part obliges incoming vessels to exchange their ballast water at least 200 nautical miles offshore in a minimum depth of $200 \mathrm{~m}$. The USA, not a signatory to the BW Convention, implemented a similar requirement. A study assessing ballast water exchanges in the USA from 2005 to 2007 found that most vessels abide with this rule, however, especially vessels that journeyed along the South and North American coasts still exchange their ballast water in coastal areas frequently (Miller et al. 2011). Similar results were obtained by a study targeting the Taiwanese maritime cargo sector showing that up to $30 \%$ of the surveyed ships exchange ballast water closer to shore than 200 nautical miles (Liu et al. 2014).

The second part of the BW Convention restricts the total amount of viable organisms in discharged ballast water to up to ten with a size of $>50 \mu \mathrm{m} \mathrm{m}^{-3}$ plus up to ten with a size of $<50 \mu \mathrm{m} \mathrm{ml}^{-1}$ (IMO 2004). To meet these restrictions, vessels are obliged to install ballast water treatment plants (e.g., electro-chlorination, UV treatment, and filtration). Given those conditions, Reusser et al. (2013) developed a model to predict the invasion rate per year through foreign ballast water discharge in the US Pacific Coast. Based on existing invasive species records and assuming a linear relationship between discharged organisms and successful invasions, they calculated that a new invasion would only occur every $10-100$ years.

Shipping routes and source regions of ballast water affect the survivability of organisms at the ship's destination (Verling et al. 2005). For example, do transport routes through the Panama Canal expose attached specimens to tropical and partially freshwater conditions leading to temperature and osmotic stress (Miller and Ruiz 2014). The BW Convention requires ships to keep records of ballast water activities, so that uptake areas can be compared to discharge areas on demand and high risks of introductions can be avoided. Additionally, port states are empowered to conduct ballast water controls on incoming foreign ships and, if necessary, impose sanctions.

Still, a minimum risk of biointroduction remains and is positively correlated to the amount of ballast water discharged in an area (Reusser et al. 2013). This is important to consider in major ports serving as hubs for international maritime trade such as Shanghai, Singapore, or Rotterdam. Moreover, a study of the Chinese ballast water capacity confirmed the rising amount of ballast water in line with the growing maritime transport sector (Zhang et al. 2017). 


\subsubsection{Mariculture}

Many marine species have been intentionally transported across broad geographical distances to be husbanded in aquacultures. The largest contributors to the global mariculture industry are Asian countries with China being by far the most important among them (FAO 2016). Other countries, such as Norway, Chile, and Indonesia have fast-growing mariculture industries as well (Buschmann et al. 2009). The most important cultured organisms worldwide are finfish, mollusks, crustaceans, and seaweed species. In 2014, 580 aquatic species have been registered with the FAO as husbanded species (FAO 2016). These species are often nonindigenous in the place where they are kept, meaning an escape would directly lead to an introduction into the new habitat. Examples for intentionally introduced species are the Pacific oyster Crassostrea gigas, domesticated salmon, and many seaweed species (Naylor et al. 2001). In contrast, accidental introductions may occur due to associated hitchhikers such as parasites, algae (e.g., Codium fragile), and various fouling species that live on or in aquaculture gear and husbanded species (Naylor et al. 2001).

Focusing on introductions to urban areas, Padayachee et al. (2017) investigated the taxa composition introduced by several marine vectors and found a significant difference between the categories Mariculture and Fisheries. Vertebrates were almost exclusively introduced for cultivation, while plants dominated, and were exclusive to, the equipmentfacilitated arrivals. The continuous transfer of equipment and seed stock between maricultures has an especially high potential of species introduction (Forrest and Blakemore 2006). One striking example for this is the kelp Undaria pinnatifida, used for mariculture. It arrived to Europe alongside the Pacific oyster and has since been spread independently of oyster cultivation for farming or as a fouling species and recently reached German waters (Schiller et al. 2018). This was largely enabled by its tolerance to various conditions, including surviving overland transport on boat hulls or ropes (Bollen et al. 2017).

After vessel fouling, shellfish farming is considered the second most important vector for the 277 registered nonindigenous seaweeds worldwide. Especially red corticated algae, but also a variety of other taxa, live in association with farmed shellfish (Williams and Smith 2007). Seaweed mariculture itself is only a minor but efficient way of seaweed introductions, because farmed algae are specifically chosen for their competitiveness (Williams and Smith 2007). Interestingly, seaweed mariculture is the fastestgrowing sector of aquaculture posing one-quarter of the global volume produced by aquaculture (FAO 2016). This growth is mainly due to seaweed farms in Indonesia and China that were established during the last 20 years. Between 2004 and 2014, the global aquaculture industry has grown rapidly and the percentage share of total worldwide fish harvest increased from $31.1 \%$ to $44.1 \%$ (wild catches and aquaculture products including non-food uses; FAO 2016). While regulations on an international level are missing, there are some examples for guidelines of the treatment of aquaculture organisms and gear, proposing sterilization prior to moving it to a new location. An example is the Australian National Biofouling Management Guidelines for the Aquaculture Industry that proposes different treatment methods such as exposures to air, fresh water, heat, or chemicals (NSPMMPI 2013).

\subsubsection{Static Maritime Structures}

There is a growing number of various static maritime structures (SMS), which are occasionally relocated and thus pose a risk to transport marine NIS or serve as stepping stones (i.e., oil and gas platforms, offshore wind farms, navigational buoys, non-cargo barges, and dry docks; Iacarella et al. 2018). Most SMS are characterized by their large and complex wetted surface area (WSA), providing space for fouling organisms, which, in turn, may attract predators (Friedlander et al. 2014; Todd et al. 2018). These artificial communities often differ from surrounding species assemblages (Stachowicz et al. 2002). Oil and gas platforms represent a major part of SMS and will therefore be the main focus of this section.

After being stationary for years, oil and gas platforms may be moved to a new service location, for repair, or decommission. To be able to navigate, they are either equipped with engines, towed by tug vessels (wet-tow), or carried on heavy lifting ships (dry-tow; Robertson et al. 2018). The former two options pose a risk for NIS dispersal, because platforms stay in the water during transport and are transported at very low speed $(<8$ knots), allowing associated organisms to travel along. In contrast to vessel fouling, translocated oil and gas platforms may introduce entire ecosystems to new geographical areas, including large sessile and mobile species across all trophic levels from algae to vertebrates (Ferreira et al. 2006; Yeo et al. 2009). Incidences of stranded or intentionally moved oil and gas platforms prove the introduction of a range of invertebrate species (Foster and Willan 1979; Ferreira et al. 2006; Page et al. 2006; Yeo et al. 2009), as well as fish species (Yeo et al. 2009; Wanless et al. 2010; Pajuelo et al. 2016).

Abandoned oil and gas platforms are frequently transformed into artificial reefs instead of being decommissioned ("rigs to reefs"; reviewed by Bull and Love 2019), because they foster entire marine ecosystems and due to high demolishment costs. This practice is largely unregulated with respect to its biological implications, an issue in need of addressing, considering that a large number of the roughly 
7000 oil platforms worldwide were already reaching the end of their service time in 2003 (Hamzah 2003).

Iacarella et al. (2018) emphasized that regulations concerning marine NIS introductions through SMS are still missing. This is especially worrying considering that the Arctic might become more available for commercial use, including drilling operations, with decreasing sea ice.

\subsubsection{Marine Litter}

We have long known about how ocean currents can transport a wide variety of structures, which may then serve as a raft for fouling species (Guppy 1917; Thiel and Gutow 2005; Wichmann et al. 2012). The presence of floating plastic debris in the oceans has increased tremendously in recent decades and continues to grow (PlasticsEurope 2013). Due to this increment of potential vectors, we very well might be on the brink of a new era for marine invasions.

The exact sources of anthropogenic debris are often unknown, since trajectories of floating objects are hard to track, being influenced by seasonal variations in wind and current conditions (Kiessling et al. 2015). The United Nations Joint Group of Experts on the Scientific Aspects of Marine Pollution (GESAMP) have estimated that land-based sources account for up to $80 \%$ of the world's marine litter, $60-95 \%$ of the waste being plastic debris (Sheavly 2005). However, shipping activities have also been a major source of marine litter (Scott 1972). Despite agreements to forbid ship waste dumping (London Dumping Convention, promulgated in 1972; Lentz 1987), compliance and enforcement still pose significant challenges (Carpenter and Macgill 2005). In fact, in some regions up to $95 \%$ of all litter items are shipping-related (Van Franeker et al. 2011), and debris composition in the Baltic Sea and North Pacific Ocean leaves little doubt that ocean-based sources are major contributors to marine debris (Moore and Allen 2000; Fleet et al. 2009; Keller et al. 2010; Watters et al. 2010; Schlining et al. 2013).

The predominance of plastic as floating litter and as accumulated debris on shorelines is not due to the amounts in which it is produced relative to other types of waste, but to its remarkable persistence and durability (Andrady 2015). The long life expectancy of a piece of plastic contrasts to the natural processes of consumption and decomposition that organic flotsam eventually undergoes (Vandendriessche et al. 2007). It is because of this persistence that today we are facing the possibility of human litter more than doubling rafting opportunities, particularly at high latitudes (Barnes 2002), and potentially propagating fauna outside of their native ranges (Barnes et al. 2009; Gregory 2009) and up to the most remote polar marine environments (Barnes et al. 2010; Lusher et al. 2015). Because of its overall high numbers, plastic debris offers rafting opportunities that quantita- tively surpass other floating substrata in the oceans. As Goldstein et al. (2012) suggest, many species may no longer be limited by the availability of suitable substrata to adhere to. On top of enhancing transport of rafting communities, the availability of plastic may favor the transport of certain species over others. This is because rafting communities on litter and, e.g., macroalgae are described as similar, but less species rich in the former (Winston et al. 1997; Gregory 2009).

Over 1200 taxa have been associated with natural and anthropogenic flotsam (Thiel and Gutow 2005), and many organisms and potential invaders were first described on marine litter (Jara and Jaramillo 1979; Stevens et al. 1996; Winston et al. 1997; Cadée 2003). One most notable event was the record of a 188-ton piece of a former dock, dislodged during a tsunami in Japan in 2011, stranded in Oregon and accounting for the first record of over 100 species non-native to the west coast of the USA (Choong and Calder 2013). While samples taken from beach litter collections show a bias towards sessile organisms with hard calcified structures (Winston et al. 1997; Gregory 2009), debris collected afloat include a higher diversity of soft-bodied and/or motile species (Astudillo et al. 2009; Goldstein et al. 2014). Overall, cnidarians, bryozoans, mollusks, and crustaceans seem to be the most abundant taxa registered. Today, we know plastic can host a variety of pathogens: the ciliate Halofolliculina sp., which targets coral skeletal structures (Goldstein et al. 2014), potential human and animal pathogens of the genus Vibrio (Zettler et al. 2013), and dinoflagellates known to cause harmful algal blooms (Masó et al. 2003).

What ensures colonization and survival during transport on a plastic raft? Kiessling et al. (2015) reviewed 82 publications with the aim of characterizing marine debris rafters, their biological traits, and identifying the specific conditions rafters face in order to survive their voyages. Their results suggest that a majority of species act as facultative rafters (77\%), as fully sessile (59\%), and as suspension feeders (72\%). This can easily be compared to communities of algae rafts, which are more complex at the structural level, and more capable of hosting mobile species with different feeding patterns (Thiel and Gutow 2005).

Colonization might influence certain characteristics of a plastic raft. Floating behavior might be altered, as the added weight of rafters may stabilize an otherwise highly buoyant and unbalanced object. This would increase colonization probability (Bravo et al. 2011) and the succession of the rafting community, but heavy fouling on a plastic item may increase the raft's weight and cause it to sink (Ye and Andrady 1991; Barnes et al. 2009). If this causes death and loss of rafters, it may result in decolonization and resurfacing of the item (Ye and Andrady 1991), extending the life of plastic as a vector. The size of a particular piece of debris can also play a part in influencing the species richness and 
density of organisms rafting on it. Studies have shown a positive correlation between higher taxonomic richness and a larger surface area of plastic debris (Carson et al. 2013; Goldstein et al. 2014). However, this may be due to stochastic effects, biased sampling efforts (smaller items sink faster when colonized by fewer organisms) or other characteristics of the raft such as stability (Goldstein et al. 2014).

Although it is not expected that marine litter opens up novel pathways that are not available for other rafting materials (Lewis et al. 2005), it is more durable, more pervasive, and travels slower in comparison with vessel hulls, factors that might favor the survival of rafters (Barnes 2002). Therefore, the presence of plastic debris in the ocean might be adding another dimension to rafting and dispersal opportunities.

Today, we are familiar with calls to consider plastic as hazardous materials (Rochman et al. 2013), investing in better controls for waste management (European Commission 2018), and seeing strong lobbying in certain sectors of social media. As Rech et al. (2016) state, our main research priorities should center around estimating the impact of marine litter on NIS dispersal, and identifying sources and sinks by better understanding behavior of debris in ocean currents. Future research should consider unifying sampling methods to obtain comparable results and including base knowledge of local communities to better monitor arrivals of NIS while continuing our advance in taxonomic and genetic identification methods to be able to better identify species that might be cryptic or yet unknown to us (Carlton and Fowler 2018).

Finally, recognizing that the plastic problem is theoretically an avoidable one, research should be accompanied by management that aims in the direction of education and public awareness, the surveillance and protection of sink zones, and the reduction of production through taxation and banning.

\subsubsection{Climate Change}

Hellmann et al. (2008) identified possible ways in which climate change may affect NIS either directly or by influencing their competitors or dispersal: Firstly, climate change alters traits of habitats such as temperatures and $\mathrm{CO}_{2}$ concentrations, which may reduce environmental constraints for marine invaders and diminish native species' competitiveness. Ultimately, this would increase the establishment rate of NIS in a new habitat. Secondly, climate change alters human-induced propagule pressure by affecting maritime tourism, cargo, and recreational activities. Finally, Hellmann et al. (2008) argued that climate change may lead to rangeshifts of species, a trend that has been documented multiple times in the scientific literature, and which does not only affect NIS, but also native species (Sorte et al. 2010b; Carlton
2011; Wernberg et al. 2011; Canning-Clode and Carlton 2017; Martínez et al. 2018).

Although marine range-shifts occurs at a slower rate than marine introductions through anthropogenic vectors, the impacts on ecological communities in both scenarios can be very similar (Sorte et al. 2010a) and thus range-shifts due to human-induced climate change may be considered a type of anthropogenic introduction.

Climate change predictions include not only a change in the overall temperature but also the increasing climate variability (Rhein et al. 2013). Aperiodic cold snaps have been observed to reduce the number of invasive species (CanningClode et al. 2011). In this particular example, a cold snap in January 2010 in Florida, USA caused high mortalities of many marine organisms, among them the invasive porcelain crab Petrolisthes armatus (Firth et al. 2011; Kemp et al. 2011). Testing the survivability of $P$. armatus in cold water treatments, Canning-Clode et al. (2011) found that abnormal cold temperatures decrease the population of the invasive crab. Cold snaps limiting NIS might be relevant worldwide, but do not balance out climate change-induced range-shifts of NIS (Canning-Clode and Carlton 2017). In fact, individual examples show that NIS may expand to a broader distribution range after its population got reduced by a cold snap (Crickenberger and Moran 2013). Canning-Clode and Carlton (2017) assumed that NIS surges will eventually outnumber NIS setbacks along with predicted warming climate. This is underlined by several studies showing the beneficial impact of warmer water on NIS (Stachowicz et al. 2002; Sorte et al. 2010b; Kersting et al. 2015).

Stachowicz et al. (2002) found several benefits for nonnative fouling species in warmer water temperatures. During a 10-year monitoring campaign, starting in 1991, they found a positive correlation between mean temperature and total recruitment of NIS, whereas the opposite trend was observed for native species. Additionally, nonnative fouling species started their recruitment earlier in warmer waters, a remarkable advantage over native species. Stachowicz et al. (2002) also tested the growth of two non-native and one native ascidian species under different water temperatures resulting in faster growth of the former in warm water conditions. Sorte et al. (2010b) conducted mortality experiments with four native and seven nonnative sessile species (bryozoans, colonial and solitary tunicates, and hydroids) in increased temperature treatments. They observed that the temperature at which only $50 \%$ of the species were alive is $3{ }^{\circ} \mathrm{C}$ higher for NIS than for native species, suggesting that NIS are more resistant to abnormally high temperatures.

Overall, there seems to be a trend of species shifting their ranges polewards along the continental coasts with proceeding climate change (Müller et al. 2009; Sorte et al. 2010a; Wernberg et al. 2011; Morley et al. 2018). 


\subsection{Forecasting}

Of all transferred species, only a small number become truly invasive (see the "tens rule"; Williamson and Fitter 1996). Identifying the potential of an introduced species for dispersal and establishment can be useful in risk assessment. In this cause, Ecological Niche Modelling (ENM) and Species Distribution Models (SDM) can be of great help when predictions of species' potential distributions are needed. Conservation biology can, besides other applications (Guisan and Thuiller 2005; Gavin et al. 2014), profit from SDMs for risk assessment of invasions (Peterson 2003; Thuiller et al. 2005; Seebens et al. 2016). An ecological niche represents an $n$-dimensional (e.g., food-availability and temperature gradient) space in which a species can thrive (Hutchinson 1957). For distribution modelling, a model is usually calibrated on a species' niche and then projected onto the geographic space of interest. Here, the calibration process is conducted on available information of a species' known distribution and/or biological traits and the projection area is compared with the needs of a species. Like that, the suitability of an area can be evaluated and visualized. Calibration and projection can be done on historical and present-day data and allow predictions for simulated environmental conditions as, e.g., for future or past climate scenarios. The importance of invasionrisk assessments is underlined by Leung et al. (2002) who developed a bio-economic model as a framework to assess costs and benefits of invasions and their prevention efforts. Leung et al. (2002) demonstrated that investment in prevention over damage repair is to be preferred for society. For risk assessments, the recognition of suitable habitat of a species is of central interest. Hence, ENM is an important tool for policy makers to evaluate and to react to possible invasions before they can get economically or ecologically out of hand. Although ENM/SDM-related publications have become more and more abundant and yield valuable information for a diverse array of interests, there is a huge gap in the number of available publications between the terrestrial and the aquatic realm and between organizational organism levels. While a lot of studies are accessible for especially terrestrial higher plants, mammals, and birds, aquatic (small) taxa are still underrepresented (Soininen and Luoto 2014). Hence, methodological aspects in the following section are partly explained based on terrestrial studies. To understand the underlying concept of ecological niche modelling, Soberon and Peterson (2005) elaborated the work of Pulliam (2000) and presented the BAM-diagram. The BAM diagram consists of a set of suitable biotic, abiotic and accessible (movement) spaces. Thus, A represents the fundamental niche and the intersection of $\mathrm{B}$ and $\mathrm{A}$ represents the realized niche of a species. The fundamental niche is the space which can theoretically be inhabited by a species. Contrary, the realized niche represents the fundamental niche which is actually inhabited but truncated due to abiotic or biotic factors. M can contain naturally accessible regions as well as regions which are reachable through anthropogenic influence. Restrictions of M can be inherent (dispersal capacity of a species) or external and either of natural (e.g., land bridges) or artificial character (e.g., dams; Watters 1996, Ovidio and Philippart 2002). In the context of this paper, $M$ (with respect to dispersal vectors) and $\mathrm{A}$ (with respect to changing climate) play major roles. Implementation of B (as biotic interactions) into models is still an area of investigation and rather casespecific than following established concepts.

\subsubsection{Limitations of Models Through Knowledge Gaps}

Distribution modelling is the projection of an identified niche from one geographic range to another under the presumption that species occupy the same conditions in both regions (Peterson and Vieglais 2001). Therefore, environmental data (predictor variables) in a species' distributional range is correlated with occurrence data (response variable). Nowadays, more and more databases are becoming available to provide researchers with valuable data for predictors (e.g., bio-oracle, worldclim, MerraClim) as well as distributional data (e.g., gbif, iobis) in addition to available primary sources (e.g., herbaria, museum collections, scientific reports, field guides, citizen science projects). Although correlative models have great predictive power, they can only identify the realized niche based on available distributional and environmental data. However, species are not necessarily in equilibrium with their environment and not all suitable environmental combinations might be represented in the distributional training range (Jackson and Overpeck 2000). Hence, these models may underestimate the fundamental niche of a species, leading to narrowed projections of suitable habitat (Kearney and Porter 2009; Martínez et al. 2015). Additionally, even in native distributional ranges parts of populations are in fact sink populations (Soberon and Peterson 2005) and might, therefore, reflect unsuitable environmental conditions for reproduction but suitable for survival. There are many other possible cases, in which the observed distribution of a species does not cover all suitable environmental conditions (e.g., sampling bias, seasonality, anthropogenic influences, and recent introduction). In any case, models based on unfilled niches could lead to erroneous assumptions on suitability of habitat for a given species (Peterson 2005). Likewise, projections into niche space beyond the identified realized niche can only be speculative. Therefore, models based on physiological knowledge are an important addition to classic correlative models (Kearney and Porter 2009). These mechanistic models make use of physiological 
knowledge (e.g., survival thresholds or performance over environmental gradients) to identify abiotically suitable spaces (Kearney and Porter 2009; Buckley et al. 2010; Diamond et al. 2012; Martínez et al. 2015). Identification of physiological limits is more laborious than correlative modelling, but these models are not subject to incomplete distribution data. In 2017, the GlobTherm database has been launched (Bennett et al. 2018), which includes experimentally determined thermal tolerances for more than 2000 aquatic and terrestrial species, providing a promising tool for future more holistic modelling approaches. While correlative models might assume too narrow niches, mechanistic models might, in ignorance of biological influences, assume too wide niches. The resulting discrepancies might bear the potential to investigate factors influencing the prevalence of a species and be useful in invasion risk assessment.

\subsubsection{Invasions and Niche Shifts}

It is a central assumption of SDM that species do occupy the same niche in their novel range as in their native range and across time periods. However, this has been subject of debates and evaluation studies in the past under the term "niche shift." This term implies changes in the realized niche of a species with respect to the centroid of the niche, the margins, and/or frequency of occupied environmental conditions (Guisan et al. 2014). Although studies have been published, which suggest niche shifts in invaded territories (e.g., Maron et al. 2004; Fitzpatrick et al. 2006; Broennimann et al. 2007), ecological niches have also been shown to be a rather conservative feature of species' and can be transferred to other than the native regions (Prinzing et al. 2001; Broennimann et al. 2007; Tingley et al. 2009; Petitpierre et al. 2012). Petitpierre et al. (2012) investigated 50 holarctic terrestrial plant species from herbs to trees and found niche expansion of more than $10 \%$ in the invaded range for only $14 \%$ of the studied species. Furthermore, they stated that genetic admixing (repeated introductions or hybridization) or reduced competition in the novel range do not automatically lead to substantial niche expansions. Ecological niches are even conserved over evolutionary time scales (i.e., several million years), as has been shown by Peterson et al. (1999). The authors built ecological niche models for 37 sister taxa of birds, mammals, and butterflies, and were able to reciprocally predict the geographical distribution of the respective sister taxon with high accuracy. Larger niche dissimilarity was found only on the higher taxonomic family level. Naturally, due to shared ancestry, niches of sister taxa tend to be highly similar. This was demonstrated by comparison to more distant taxa and to what can be expected from their environmental background alone (Warren et al. 2008). However, comparison of ecological niches of sister taxa and respective outlier groups does not necessarily indicate close phylogenetic relationship (Warren et al. 2008). Hence, not only phylogenetic relationship but also the environmental framework defines the species' niches. This is in line with Ackerly (2003): Species' niches are maintained throughout space and time and adaptation in specific traits seems to have a more stabilizing function in maintaining this niche. Adaptive evolution still may occur under the following scenarios: When a species colonizes islands in environmental space (not necessarily equivalent with geographical space), in trailing edge populations during migrations, or adaptation within the occupied niche space (due to environmental changes) (Ackerly 2003). To identify true niche shifts, Guisan et al. (2014) propose to build ENMs with gradually trimmed environmental data from the native and novel range and to investigate the effects of rare climatic conditions on resulting niche overlap metrics.

Large niche shifts can erroneously be assumed when species niches are derived from unfilled niches. For example, if a species occupies environmental conditions in a new geographic region (e.g., an invaded site) which are not found in its native range. In fact, populations rather persist at the edges than in the center of their historical distributional range (Lomolino and Channell 1995), and building a niche model on occurrence data from a certain time span can only yield a snapshot of the actual niche and might result in biased projections (Faurby and Araújo 2018). Including historical distributional and environmental data may be important to prevent modelling of biased niches. Also the findings of Peterson et al. (1999) might allow to considerably enhance the available information on tolerated environmental conditions by carefully including the realized niches of sister taxa. Distributional ranges and concomitant realized niches are massively narrowed through anthropogenic influences (e.g., extinctions or displacement; Lomolino and Channell 1995) but, in contrast, can become enormously enhanced through dispersal events (anthropogenically through increasing global trade and aquaculture, Ruiz et al. 1997, or naturally through drift, Waters 2008). An example of how unfilled niches may pose problems for accurate ecological niche modelling is given by Peterson (2005): He explained how non-equilibrium distributional data may lead to biased niche assumptions and hence underestimate a species' niche as in the case in Ganeshaiah et al. (2003). Ganeshaiah et al. (2003) modelled the ecological niche of the terrestrial sugarcane woolly aphid (Ceratovacuna lanigera) to predict its invasion potential across India. However, they used distributional records which were collected during the process of migration, and therefore could not cover the whole range of suitable environmental conditions. Thus, the suitable range was underestimated and Peterson (2005) suggested using native distributional data to train an ENM in order to capture the 
whole ecological niche for more realistic information on potential habitat.

While biotic interactions play a central role in ecology, they are only recently being integrated into niche modelling. Their former omission could be due to either the difficulties of implementing highly complex and dynamic biotic interactions, population and dispersal dynamics or because of the general assumption that rather abiotic (climatic) factors are the main drivers of species distributions (Woodward and Williams 1987). Models based on climatic variables alone have good predictive power, but biotic interactions can be of major importance (Araújo and Luoto 2007; Soininen et al. 2013). However, including biotic interactions does not necessarily lead to an increase in predictive power (Raath et al. 2018), but, in contrast, might even lead to a decrease (Silva et al. 2014). Nevertheless, they can be of great importance when it comes to predicting invasion success, as has been shown by Silva et al. (2014) for the crown-of-thorns sea star.

\subsubsection{Assessing Invasions}

Predicted high suitability of a certain range does not imply a risk of invasion. Species distribution models give information on how well a certain area matches the requirements of a certain species. Intact environments and species communities as well as geographic obstacles may prevent the invasion of a species. In fact, successful invasions often follow several failed introductions (Sax and Brown 2000) and although a potentially suitable habitat might be available, intrinsic and extrinsic factors are able to prevent a successful invasion. Firn et al. (2011) did not find evidence for a general pattern of higher abundance in non-native ranges of introduced species ("invasion paradox," Sax and Brown 2000). Only a small fraction of the 26 investigated species did show a higher abundance in the new range. The other species were as abundant as in their native ranges or less abundant.

Simple ecological niche models can give good estimations of the extent of range shifts under projected climate conditions. However, at finer scales, models can be improved by including high-detail data for dispersal capacity and landuse data when it comes to accurate local predictions (Fordham et al. 2018). Even if data on dispersal capacity cannot be included in a model, general predictions of invasion risk are possible. Thuiller et al. (2005) showed that invasion prediction based on climatic variables in combination with economic data such as tourism and trade intensity is a usable and important tool in identifying invasion risk between regions at a global scale. Tourism and trade were used as proxies for propagule pressure from source regions (namely, South Africa) to target regions. For risk assessment of marine bioinvasions via ports and main shipping routes, an intermediate distance between origin and recipient port of
8000 to $10,000 \mathrm{~km}$ seems to be significant for high-risk assignment (Seebens et al. 2013). Generally, main traffic highways across the oceans exist, of which some have higher invasion probabilities than others (e.g., between Asia \& Europe and Asia \& North-America). Seebens et al. (2016) successfully developed a model to predict migrations of marine algae-based only on occupied environmental conditions and marine traffic data. Furthermore, they used historical invasion data to identify the invasion risk for ecoregions around the world and were able to identify the respective invasion probability.

Predictive models are not equally good among taxa. Soininen et al. (2013) found that predictive power of species distribution models decreases with decreasing body size of the organism under investigation to exceptionally low values when compared to taxonomic groups of larger body size. This might be due to the fact that especially small planktonic taxa might be drifted to unsuitable habitats and therefore exhibit source and sink populations alike within their distributional range. Soininen and Luoto (2014) further investigated how species-specific traits can influence the predictive power of distribution models. They investigated 4911 AUC values ("Area under curve," an indicator of predictive power of a model) of 50 publications on taxonomically widespread organisms. One conclusion was that predictability increases with body size, which might be due to the fact that smaller organisms are more prone to colonization-extinction dynamics, fine-scale environmental fluctuations, and have less niche plasticity than larger taxa. Interestingly, they did not find a trend in predictability over dispersal mode (i.e., passive, non-flying active, and flying) and thereby underlined the findings of Kharouba et al. (2013). Furthermore, niches of organisms from lower trophic levels might be more reliably predicted by abiotic predictors alone than from higher trophic levels (Soininen and Luoto 2014). However, this notion could not be verified in an earlier comparative study by Huntley et al. (2004) on 306 higher plant, insect, and bird taxa.

\subsection{Conclusions}

Under increasing globalization and blue growth (i.e., marine cargo shipping, mariculture, oil and gas drilling, and deepsea mining), human-mediated vectors will continuously homogenize marine species assemblages across biogeographical regions. Although ballast water is the only vector with a worldwide binding regulation, guidelines to face the threat of invasions are constantly improved and official frameworks are beginning to be implemented on a broader scale. For example, the European Union is now considering plastic pollution as a threat and carrying out mitigation strategies such as banning certain one-use products. An efficient 
starting point for the prevention of bionvasions could be to control the number of organisms attached to vessel hulls and in ballast water tanks prior the vessel's arrival in hub-ports.

Species Distribution Models (SDMs) have the potential to become powerful and valuable tools in identifying high-risk areas and species and developing mitigation strategies. To achieve this, we conclude that two things are necessary: quantifying vectors (e.g., wetted surface area (WSA) of ships), and gathering non-indigenous species records and making these publicly available. Moreover, quantifying human-mediated vectors may also facilitate the opportunity of performing holistic cross-vector comparisons. One example would be to compute WSA values and complexity degrees, not only for ships but also for floating plastic and oil platforms, which would enable realistic comparisons between these three vectors. At the onset of increased economic exploration in polar regions, it is imperative to push the understanding of bioinvasions and lower the risk of potential ecosystem shifts due to unintended species introductions.

\section{Appendix}

This article is related to the YOUMARES 9 conference session no. 13: "Higher temperatures and higher speed - Marine Bioinvasions in a changing world." The original Call for Abstracts and the abstracts of the presentations within this session can be found in the Appendix "Conference Sessions and Abstracts", Chapter "9 Higher temperatures and higher speed - Marine Bioinvasions in a changing world", of this book.

\section{References}

Ackerly DD (2003) Community assembly, niche conservatism, and adaptive evolution in changing environments. Int J Plant Sci 164:S165-S184

Alpert P, Bone E, Holzapfel C (2000) Invasiveness, invasibility and the role of environmental stress in the spread of non-native plants. Perspecti Plant Ecol Evol Syst 3:52-66

Anderson LG, Rocliffe S, Haddaway NR et al (2015) The role of tourism and recreation in the spread of non-native species: a systematic review and meta-analysis. PLoS One 10:e0140833

Andrady AL (2015) Persistence of plastic litter in the oceans. In: Bergmann M, Gutow L, Klages M (eds) Marine anthropogenic litter. Springer, Cham, pp 57-72

Araújo MB, Luoto M (2007) The importance of biotic interactions for modelling species distributions under climate change. Glob Ecol Biogeogr 16:743-753

Astudillo JC, Bravo M, Dumont CP et al (2009) Detached aquaculture buoys in the SE Pacific: potential dispersal vehicles for associated organisms. Aquat Biol 5:219-231

Barnes DK (2002) Biodiversity: invasions by marine life on plastic debris. Nature 416:808-809
Barnes DK, Galgani F, Thompson RC et al (2009) Accumulation and fragmentation of plastic debris in global environments. Philos Trans R Soc B Biol Sci 364:1985-1998

Barnes DK, Walters A, Gonçalves L (2010) Macroplastics at sea around Antarctica. Mar Environ Res 70:250-252

Bennett JM, Calosi P, Clusella-Trullas S et al (2018) GlobTherm, a global database on thermal tolerances for aquatic and terrestrial organisms. Sci Data 5:180022

Blackburn TM, Pyšek P, Bacher S et al (2011) A proposed unified framework for biological invasions. Trends Ecol Evol 26:333-339

Bollen M, Battershill CN, Pilditch CA et al (2017) Desiccation tolerance of different life stages of the invasive marine kelp Undaria pinnatifida: potential for overland transport as invasion vector. J Exp Mar Biol Ecol 496:1-8

Boudouresque CF, Verlaque M (2002) Biological pollution in the Mediterranean Sea: invasive versus introduced macrophytes. Mar Pollut Bull 44:32-38

Bravo M, Astudillo JC, Lancellotti D et al (2011) Rafting on abiotic substrata: properties of floating items and their influence on community succession. Mar Ecol Prog Ser 439:1-17

Broennimann O, Treier UA, Muller-Scharer H et al (2007) Evidence of climatic niche shift during biological invasion. Ecol Lett 10:701-709

Buckley LB, Urban MC, Angilletta MJ et al (2010) Can mechanism inform species' distribution models? Ecol Lett 13:1041-1054

Bull AS, Love MS (2019) Worldwide oil and gas platform decommissioning: a review of practices and reefing options. Ocean Coast Manage 168:274-306

Buschmann AH, Cabello F, Young K et al (2009) Salmon aquaculture and coastal ecosystem health in Chile: analysis of regulations, environmental impacts and bioremediation systems. Ocean Coast Manage 52:243-249

Cadée M (2003) Een vondst van de Atlantische Pareloester Pinctada imbracata (Röding, 1789) in een plastic fles op het Noordwijkse strand. Het Zeepard 63:76-78

Campbell ML, Keith I, Hewitt CL et al (2015) Evolving marine biosecurity in the Galapagos Islands. Manag Biol Invasion 6:227-230

Canning-Clode J, Carlton JT (2017) Refining and expanding global climate change scenarios in the sea: poleward creep complexities, range termini, and setbacks and surges. Divers Distrib 23:463-473

Canning-Clode J, Fowler AE, Byers JE et al (2011) 'Caribbean creep' chills out: climate change and marine invasive species. PLoS One 6:e29657

Carlton JT (1979) Introduced invertebrates of San Francisco Bay. In: Conomos TJ (ed) San Francisco, the urbanized estuary. American Association for the Advancement of Science, San Francisco, pp 427-444

Carlton JT (2011) Invertebrates, marine. In: Simberloff D, Rejmánek M (eds) Encyclopedia of biological invasions, vol 3. University of California Press, Berkeley

Carlton JT, Fowler AE (2018) Ocean rafting and marine debris: a broader vector menu requires a greater appetite for invasion biology research support. Aquat Invasions 13:11-15

Carpenter A, Macgill SM (2005) The EU Directive on port reception facilities for ship-generated waste and cargo residues: the results of a second survey on the provision and uptake of facilities in North Sea ports. Mar Poll Bullut 50:1541-1547

Carson HS, Nerheim MS, Carroll KA et al (2013) The plasticassociated microorganisms of the North Pacific gyre. Mar Pollut Bull 75:126-132

Casas G, Scrosati R, Piriz ML (2004) The invasive kelp Undaria pinnatifida (Phaeophyceae, Laminariales) reduces native seaweed diversity in Nuevo Gulf (Patagonia, Argentina). Biol Invasions $6: 411-416$

Choong HH, Calder DR (2013) Sertularella mutsuensis Stechow, 1931 (Cnidaria: Hydrozoa: Sertulariidae) from Japanese tsunami debris: 
systematics and evidence for transoceanic dispersal. BioInvasions Rec 2:33.38

Cohen AN, Carlton JT (1998) Accelerating invasion rate in a highly invaded estuary. Science 279:555-558

Crickenberger S, Moran A (2013) Rapid range shift in an introduced tropical marine invertebrate. PLoS One 8:e78008

Diamond SE, Nichols LM, McCoy N et al (2012) A physiological traitbased approach to predicting the responses of species to experimental climate warming. Ecology 93:2305-2312

Endresen Ø, Sørgård E, Sundet JK et al (2003) Emission from international sea transportation and environmental impact. J Geophys Res 108:4560

European Commission (2018) A European strategy for plastics in a circular economy. European Commission, Brussels

FAO (2016) The state of world fisheries and aquaculture 2016. Contributing to food security and nutrition for all. FAO, Rome

Faurby S, Araújo MB (2018) Anthropogenic range contractions bias species climate change forecasts. Nat Clim Chang 8:252

Ferreira C, Gonçalves J, Coutinho R (2006) Ship hulls and oil platforms as potential vectors to marine species introduction. J Coas Res SI39:1340-1345

Firn J, Moore JL, MacDougall AS et al (2011) Abundance of introduced species at home predicts abundance away in herbaceous communities. Ecol Lett 14:274-281

Firth LB, Knights AM, Bell SS (2011) Air temperature and winter mortality: implications for the persistence of the invasive mussel Perna viridis in the intertidal zone of the South-Eastern United States. J Exp Mar Biol Ecol 400:250-256

Fitzpatrick MC, Weltzin JF, Sanders NJ et al (2006) The biogeography of prediction error: why does the introduced range of the fire ant over-predict its native range? Glob Ecol Biogeogr 16:24-33

Fleet D, Van Franeker JA, Dagevos Jet al (2009) Marine litter. Thematic report no. 3.8. In: Marencic H, CWSS (eds) Quality status report 2009. Wadden Sea Ecosystem no. 25. Common Wadden Sea Secretariat (CWSS), Wilhelmshaven, Germany

Floerl O, Pool TK, Inglis GJ (2004) Positive interactions between nonindigenous species facilitate transport by human vectors. Ecol Appl 14:1724-1736

Fordham DA, Bertelsmeier C, Brook BW et al (2018) How complex should models be? Comparing correlative and mechanistic range dynamics models. Glob Chang Biol 24:1357-1370

Forrest BM, Blakemore KA (2006) Evaluation of treatments to reduce the spread of a marine plant pest with aquaculture transfers. Aquaculture 257:333-345

Foster B, Willan R (1979) Foreign barnacles transported to New Zealand on an oil platform. New Zeal J Mar Fresh 13:143-149

Fowler AE, Blakeslee AM, Canning-Clode J et al (2016) Opening Pandora's bait box: a potent vector for biological invasions of live marine species. Divers Distrib 22:30-42

Friedlander AM, Ballesteros E, Fay M et al (2014) Marine communities on oil platforms in Gabon, West Africa: high biodiversity oases in a low biodiversity environment. PLoS One 9:e103709

Ganeshaiah K, Barve N, Nath N et al (2003) Predicting the potential geographical distribution of the sugarcane woolly aphid using GARP and DIVA-GIS. Curr Sci 85:1526-1528

García-Llorente M, Martín-López B, González JA et al (2008) Social perceptions of the impacts and benefits of invasive alien species: implications for management. Biol Conserv 141:2969-2983

Gavin DG, Fitzpatrick MC, Gugger PF et al (2014) Climate refugia: joint inference from fossil records, species distribution models and phylogeography. New Phytol 204:37-54

Godwin LS (2003) Hull fouling of maritime vessels as a pathway for marine species invasions to the Hawaiian islands. Biofouling 19:123-131

Goldstein MC, Rosenberg M, Cheng L (2012) Increased oceanic microplastic debris enhances oviposition in an endemic pelagic insect. Biol Lett 8:817-820
Goldstein MC, Carson HS, Eriksen M (2014) Relationship of diversity and habitat area in North Pacific plastic-associated rafting communities. Mar Biol 161:1441-1453

Gollasch S (2006) Overview on introduced aquatic species in European navigational and adjacent waters. Helgol Mar Res 60:84-89

Gregory MR (2009) Environmental implications of plastic debris in marine settings - entanglement, ingestion, smothering, hangerson, hitch-hiking and alien invasions. Philos Trans R Soc B Biol Sci 364:2013-2025

Guisan A, Thuiller W (2005) Predicting species distribution: offering more than simple habitat models. Ecol Lett 8:993-1009

Guisan A, Petitpierre B, Broennimann O et al (2014) Unifying niche shift studies: insights from biological invasions. Trends Ecol Evol 29:260-269

Guppy HB (1917) Plants, seeds, and currents in the West Indies and Azores. Williams \& Norgate, London

Guy-Haim T, Lyons DA, Kotta J et al (2018) Diverse effects of invasive ecosystem engineers on marine biodiversity and ecosystem functions: a global review and meta-analysis. Glob Chang Biol 24:906-924

Hamzah B (2003) International rules on decommissioning of offshore installations: some observations. Mar Policy 27:339-348

Hellmann JJ, Byers JE, Bierwagen BG et al (2008) Five potential consequences of climate change for invasive species. Conserv Biol 22:534-543

Huntley B, Green RE, Collingham YC et al (2004) The performance of models relating species geographical distributions to climate is independent of trophic level. Ecol Lett 7:417-426

Hutchinson GE (1957) Concluding remarks. Cold Spring Harb Symp Quant Biol 22:415-427

Iacarella JC, Davidson IC, Dunham A (2018) Biotic exchange from movement of 'static'maritime structures. Biol Invasions:1-11

IMO (2004) International convention for the control and management of ships' ballast water and sediments. International Maritime Organization, London

IMO (2011) Guidelines for the control and Management of Ship's biofouling to minimize the transfer of invasive aquatic species. International Maritime Organization, London

Jackson ST, Overpeck JT (2000) Responses of plant populations and communities to environmental changes of the late quaternary. Paleobiology 26:194-220

Jara C, Jaramillo E (1979) Hallazgo de Planes marinus Rathbun, 1914, sobre boya a la deriva en Bahía de Maiquillahue, Chile. (Crustacea. Decapoda, Grapsidae). Medio Ambiente (Chile) 4:108-113

Kauano RV, Roper JJ, Rocha RM (2017) Small boats as vectors of marine invasion: experimental test of velocity and desiccation as limits. Mar Biol 164:27

Kearney M, Porter W (2009) Mechanistic niche modelling: combining physiological and spatial data to predict species' ranges. Ecol Lett 12:334-350

Keller AA, Fruh EL, Johnson MM et al (2010) Distribution and abundance of anthropogenic marine debris along the shelf and slope of the US west coast. Mar Pollut Bull 60:692-700

Kemp DW, Oakley CA, Thornhill DJ et al (2011) Catastrophic mortality on inshore coral reefs of the Florida keys due to severe lowtemperature stress. Glob Chang Biol 17:3468-3477

Kersting DK, Cebrian E, Casado Cet al (2015) Experimental evidence of the synergistic effects of warming and invasive algae on a temperate reef-builder coral. Sci Rep5:18635

Kharouba HM, McCune JL, Thuiller W et al (2013) Do ecological differences between taxonomic groups influence the relationship between species' distributions and climate? A global meta-analysis using species distribution models. Ecography 36:657-664

Kiessling T, Gutow L, Thiel M (2015) Marine litter as habitat and dispersal vector. In: Bergmann M, Gutow L, Klages M (eds) Marine anthropogenic litter. Springer, Cham, pp 141-181 
Lentz SA (1987) Plastics in the marine environment: legal approaches for international action. Mar Pollut Bull 18:361-365

Leppäkoski E, Gollasch S, Olenin S (2013) Invasive aquatic species of Europe. Distribution, impacts and management. Springer, Dordrecht

Leung B, Lodge DM, Finnoff D et al (2002) An ounce of prevention or a pound of cure: bioeconomic risk analysis of invasive species. Proc R Soc Lond B Biol Sci 269:2407-2413

Lewis PN, Riddle MJ, Smith SD (2005) Assisted passage or passive drift: a comparison of alternative transport mechanisms for nonindigenous coastal species into the Southern Ocean. Antarct Sci 17:183-191

Liu T-K, Chang C-H, Chou M-L (2014) Management strategies to prevent the introduction of non-indigenous aquatic species in response to the ballast water convention in Taiwan. Mar Policy 44:187-195

Lomolino MV, Channell R (1995) Splendid isolation: patterns of geographic range collapse in endangered mammals. J Mammal 76:335-347

Lusher AL, Tirelli V, O'Connor I et al (2015) Microplastics in Arctic polar waters: the first reported values of particles in surface and subsurface samples. Sci Rep 5:14947

Margolis M, Shogren JF, Fischer C (2005) How trade politics affect invasive species control. Ecol Econ 52:305-313

Maron JL, Vila M, Bommarco R et al (2004) Rapid evolution of an invasive plant. Ecol Monogr 74:261-280

Martínez B, Arenas F, Trilla A et al (2015) Combining physiological threshold knowledge to species distribution models is key to improving forecasts of the future niche for macroalgae. Glob Chang Biol 21:1422-1433

Martínez B, Radford B, Thomsen MS et al (2018) Distribution models predict large contractions of habitat-forming seaweeds in response to ocean warming. Diver Distrib 24:1350-1366

Masó M, Garcés E, Pagès F et al (2003) Drifting plastic debris as a potential vector for dispersing Harmful Algal Bloom (HAB) species. Sci Mar 67:107-111

McLaughlan C, Gallardo B, Aldridge D (2014) How complete is our knowledge of the ecosystem services impacts of Europe's top 10 invasive species? Acta Oecol 54:119-130

Miller AW, Ruiz GM (2014) Arctic shipping and marine invaders. Nat Clim Chang 4:413

Miller AW, Minton MS, Ruiz GM (2011) Geographic limitations and regional differences in ships' ballast water management to reduce marine invasions in the contiguous United States. Bioscience 61:880-887

Miller AW, Davidson IC, Minton MS et al (2018) Evaluation of wetted surface area of commercial ships as biofouling habitat flux to the United States. Biol Invasions 20:1977-1990

Ministry for Primary Industries (2014) Craft risk management standard: biofouling on vessels arriving to New Zealand. Ministry for Primary Industries, Wellington

Moore SL, Allen MJ (2000) Distribution of anthropogenic and natural debris on the mainland shelf of the Southern California bight. Mar Pollut Bull 40:83-88

Morley JW, Selden RL, Latour RJ et al (2018) Projecting shifts in thermal habitat for 686 species on the north American continental shelf. PLoS One 13:e0196127

Moser CS, Wier TP, Grant JF et al (2016) Quantifying the total wetted surface area of the world fleet: a first step in determining the potential extent of ships' biofouling. Biol Invasions 18:265-277

Müller R, Laepple T, Bartsch I et al (2009) Impact of oceanic warming on the distribution of seaweeds in polar and cold-temperate waters. Bot Mar 52:617-638

Myers JH, Simberloff D, Kuris AM et al (2000) Eradication revisited: dealing with exotic species. Trends Ecol Evol 15:316-320

Naylor RL, Williams SL, Strong DR (2001) Aquaculture - a gateway for exotic species. Science 294:1655-1656
NSPMMPI (2013) National biofouling management guidelines for the aquaculture industry. Department of Agriculture and Water Resources, Canberra

Ovidio M, Philippart J-C (2002) The impact of small physical obstacles on upstream movements of six species of fish. Hydrobiologia 483:55-69

Padayachee AL, Irlich UM, Faulkner KT et al (2017) How do invasive species travel to and through urban environments? Biol Invasions 19:3557-3570

Page HM, Dugan JE, Culver CS et al (2006) Exotic invertebrate species on offshore oil platforms. Mar Ecol Prog Ser 325:101-107

Pajuelo JG, González JA, Triay-Portella R et al (2016) Introduction of non-native marine fish species to the Canary Islands waters through oil platforms as vectors. J Mar Sys 163:23-30

Petersen JK, Svane I (1995) Larval dispersal in the ascidian Ciona intestinalis (L.). evidence for a closed population. J Exp Mar Biol Ecol 186:89-102

Peterson AT (2003) Predicting the geography of species' invasions via ecological niche modeling. Q R Biol 78:419-433

Peterson AT (2005) Predicting potential geographic distributions of invading species. Curr Sci 89:9

Peterson AT, Vieglais DA (2001) Predicting species invasions using ecological niche modeling: new approaches from bioinformatics attack a pressing problem: a new approach to ecological niche modeling, based on new tools drawn from biodiversity informatics, is applied to the challenge of predicting potential species' invasions. Bioscience 51:363-371

Peterson AT, Soberón J, Sánchez-Cordero V (1999) Conservatism of ecological niches in evolutionary time. Science 285:1265-1267

Petitpierre B, Kueffer C, Broennimann O et al (2012) Climatic niche shifts are rare among terrestrial plant invaders. Science 335:1344-1348

Pimentel D, Lach L, Zuniga R et al (2000) Environmental and economic costs of nonindigenous species in the United States. Bioscience 50:53-65

Pimentel D, McNair S, Janecka J et al (2001) Economic and environmental threats of alien plant, animal, and microbe invasions. Agric Ecosyst Environ 84:1-20

Piola RF, Johnston EL (2008) The potential for translocation of marine species via small-scale disruptions to antifouling surfaces. Biofouling 24:145-155

PlasticsEurope (2013) Plastics - the facts 2013: an analysis of European latest plastics production. Available at:www.plasticseurope.org

Prinzing A, Durka W, Klotz S et al (2001) The niche of higher plants: evidence for phylogenetic conservatism. Proc R Soc Lond B Biol Sci 268:2383-2389

Pulliam HR (2000) On the relationship between niche and distribution. Ecol Lett 3:349-361

Raath MJ, le Roux PC, Veldtman R et al (2018) Incorporating biotic interactions in the distribution models of African wild silk moths (Gonometa species, Lasiocampidae) using different representations of modelled host tree distributions. Austral Ecol 43:316-327

Raffo MP, Eyras MC, Iribarne OO (2009) The invasion of Undaria pinnatifida to a Macrocystis pyrifera kelp in Patagonia (Argentina, south-west Atlantic). J Mar Biol Assoc UK 89:1571-1580

Rech S, Borrell Y, García-Vazquez E (2016) Marine litter as a vector for non-native species: what we need to know. Mar Pollut Bull 113:40-43

Reusser DA, Lee I, Frazier M et al (2013) Per capita invasion probabilities: an empirical model to predict rates of invasion via ballast water. Ecol Appl 23:321-330

Rhein M, Rintoul SR, Aoki S, Campos E et al (2013) Observations: ocean pages. In: Stocker TF, Quin D, Plattner GK et al (eds) Climate change 2013: the physical science basis. Contribution of working group I to the Fifth Assessment Report of the Intergovernmental Panel on Climate Change. Cambridge University Press, Cambridge 
Ricciardi A, Hoopes MF, Marchetti MP et al (2013) Progress toward understanding the ecological impacts of nonnative species. Ecol Monogr 83:263-282

Richardson DM, Pyšek P (2006) Plant invasions: merging the concepts of species invasiveness and community invasibility. Prog Phys Geogr 30:409-431

Robertson DR, Dominguez-Dominguez O, Victor B et al (2018) An Indo-Pacific damselfish (Neopomacentrus cyanomos) in the Gulf of Mexico: origin and mode of introduction. PeerJ 6:e4328

Rochman CM, Browne MA, Halpern BS et al (2013) Policy: classify plastic waste as hazardous. Nature 494:169

Ruiz GM, Carlton JT, Grosholz ED et al (1997) Global invasions of marine and estuarine habitats by non-indigenous species: mechanisms, extent, and consequences. Am Zool 37:621-632

Sax DF, Brown JH (2000) The paradox of invasion. Glob Ecol Biogeogr 9:363-371

Schiller J, Lackschewitz D, Buschbaum C et al (2018) Heading northward to Scandinavia: Undaria pinnatifida in the northern Wadden Sea. Bot Mar 61:365-371

Schlining K, Von Thun S, Kuhnz L et al (2013) Debris in the deep: using a 22-year video annotation database to survey marine litter in Monterey canyon, Central California, USA. Deep Sea Res 79:96-105

Scott G (1972) Plastics packaging and coastal pollution. Int J Environ Stud 3:35-36

Seebens H, Gastner MT, Blasius B (2013) The risk of marine bioinvasion caused by global shipping. Ecol Lett 16:782-790

Seebens H, Schwartz N, Schupp PJ et al (2016) Predicting the spread of marine species introduced by global shipping. Proc Natl Acad Sci U S A 113:5646-5651

Sheavly SB (2005) Sixth meeting of the UN open-ended informal consultative processes on oceans \& the law of the sea marine debris-an overview of a critical issue for our oceans. The Ocean Conservancy, June 6-10 2005

Shenkar N, Rosen D (2018) How has the invention of the shipping container influenced marine bioinvasion? Manag Biol Invasion 9:187-194

Silva DP, Gonzalez VH, Melo GAR et al (2014) Seeking the flowers for the bees: integrating biotic interactions into niche models to assess the distribution of the exotic bee species Lithurgus huberi in South America. Ecol Model 273:200-209

Soberon J, Peterson AT (2005) Interpretation of models of fundamental ecological niches and species' distributional areas. Biodivers Inform 2:1-10

Soininen J, Luoto M (2014) Predictability in species distributions: a global analysis across organisms and ecosystems. Glob Ecol Biogeogr 23:1264-1274

Soininen J, Korhonen JJ, Luoto M (2013) Stochastic species distributions are driven by organism size. Ecology 94:660-670

Sorte CJ, Williams SL, Carlton JT (2010a) Marine range shifts and species introductions: comparative spread rates and community impacts. Glob Ecol Biogeogr 19:303-316

Sorte CJ, Williams SL, Zerebecki RA (2010b) Ocean warming increases threat of invasive species in a marine fouling community. Ecology 91:2198-2204

Stachowicz JJ, Terwin JR, Whitlatch RB et al (2002) Linking climate change and biological invasions: ocean warming facilitates nonindigenous species invasions. Proc Nat Acad Sci USA 99:15497-15500

Stevens LM, Gregory MR, Foster BA (1996) Fouling Bryozoa on pelagic and moored plastics from northern New Zealand bryozoans in space and time. In: Gordon DP, Smith AM, Grant-Mackie JA (eds) Bryozoans in space and time. In: Proceedings of the 10th international bryozoology conference. NIWA, Wellington, p 321
Thiel M, Gutow L (2005) The ecology of rafting in the marine environment. II. The rafting organisms and community. Oceanogr Mar Biol Annu Rev 43:279-418

Thuiller W, Richardson DM, Pyšek P et al (2005) Niche-based modelling as a tool for predicting the risk of alien plant invasions at a global scale. Glob Chang Biol 11:2234-2250

Tingley MW, Monahan WB, Beissinger SR et al (2009) Birds track their Grinnellian niche through a century of climate change. Proc Nat Acad Sci USA 106:19637-19643

Todd VL, Lavallin EW, Macreadie PI (2018) Quantitative analysis of fish and invertebrate assemblage dynamics in association with a North Sea oil and gas installation complex. Mar Environ Res 142:69-79

Van Franeker JA, Blaize C, Danielsen J et al (2011) Monitoring plastic ingestion by the northern fulmar Fulmarus glacialis in the North Sea. Environ Pollut 159:2609-2615

Vandendriessche S, Vincx M, Degraer S (2007) Floating seaweed and the influences of temperature, grazing and clump size on raft longevity-a microcosm study. J Exp Mar Biol Ecol 343:64-73

Verling E, Ruiz GM, Smith LD et al (2005) Supply-side invasion ecology: characterizing propagule pressure in coastal ecosystems. Proc R Soc Lond B Biol Sci 272:1249-1257

Wanless RM, Scott S, Sauer WH et al (2010) Semi-submersible rigs: a vector transporting entire marine communities around the world. Biol Invasions 12:2573-2583

Warren DL, Glor RE, Turelli M (2008) Environmental niche equivalency versus conservatism: quantitative approaches to niche evolution. Evolution 62:2868-2883

Waters JM (2008) Driven by the westwind drift? A synthesis of southern temperate marine biogeography, with new directions for dispersalism. J Biogeogr 35:417-427

Watters GT (1996) Small dams as barriers to freshwater mussels (Bivalvia, Unionoida) and their hosts. Biol Conserv 75:79-85

Watters DL, Yoklavich MM, Love MS et al (2010) Assessing marine debris in deep seafloor habitats of California. Mar Pollut Bull 60:131-138

Weigle SM, Smith LD, Carlton JT et al (2005) Assessing the risk of introducing exotic species via the live marine species trade. Conserv Biol 19:213-223

Wernberg T, Russell Bayden D, Thomsen Mads S et al (2011) Seaweed communities in retreat from ocean warming. Curr Biol 21:1828-1832

Wichmann C-S, Hinojosa IA, Thiel M (2012) Floating kelps in Patagonian Fjords: an important vehicle for rafting invertebrates and its relevance for biogeography. Mar Biol 159:2035-2049

Williams SL, Smith JE (2007) A global review of the distribution, taxonomy, and impacts of introduced seaweeds. Annu Rev Ecol Evol Syst 38:327-359

Williams SL, Davidson IC, Pasari JR et al (2013) Managing multiple vectors for marine invasions in an increasingly connected world. Bioscience 63:952-966

Williamson M, Fitter A (1996) The varying success of invaders. Ecology 77:1661-1666

Winston JE, Gregory MR, Stevens LM (1997) Encrusters, epibionts, and other biota associated with pelagic plastics: a review of biogeographical, environmental, and conservation issues. In: Coe JM, Rogers DB (eds) Marine Debris. Springer, New York, pp 81-97

Woodward FI, Williams B (1987) Climate and plant distribution at global and local scales. Vegetatio 69:189-197

Wotton DM, O'Brien C, Stuart MD et al (2004) Eradication success down under: heat treatment of a sunken trawler to kill the invasive seaweed Undaria pinnatifida. Mar Pollut Bull 49:844-849

Ye S, Andrady AL (1991) Fouling of floating plastic debris under Biscayne Bay exposure conditions. Mar Pollut Bull 22:608-613 
Yeo DC, Ahyong ST, Lodge DM et al (2009) Semisubmersible oil platforms: understudied and potentially major vectors of biofoulingmediated invasions. Biofouling 26:179-186

Zenni RD, Nuñez MA (2013) The elephant in the room: the role of failed invasions in understanding invasion biology. Oikos 122:801-815
Zettler ER, Mincer TJ, Amaral-Zettler LA (2013) Life in the "plastisphere": microbial communities on plastic marine debris. Environ Sci Technol 47:7137-7146

Zhang X, Bai M, Tian Y et al (2017) The estimation for ballast water discharged to China from 2007 to 2014. Mar Pollut Bull 124:89-93

Open Access This chapter is licensed under the terms of the Creative Commons Attribution 4.0 International License (http://creativecommons. $\mathrm{org} /$ licenses/by/4.0/), which permits use, sharing, adaptation, distribution and reproduction in any medium or format, as long as you give appropriate credit to the original author(s) and the source, provide a link to the Creative Commons license and indicate if changes were made.

The images or other third party material in this chapter are included in the chapter's Creative Commons license, unless indicated otherwise in a credit line to the material. If material is not included in the chapter's Creative Commons license and your intended use is not permitted by statutory regulation or exceeds the permitted use, you will need to obtain permission directly from the copyright holder. 